$$
\begin{gathered}
\text { Departement für Pferde } \\
\text { Klinik für Pferdechirurgie } \\
\text { der Vetsuisse-Fakultät Universität Zürich }
\end{gathered}
$$

Direktor: Prof. Dr. med. vet. Anton Fürst, Dipl. ECVS

Arbeit unter Leitung von Prof. em. Dr. med. vet. Jörg A. Auer

\title{
Evaluation of a press-fit Osteochondral Poly(ester-urethane) Scaffold in a Rabbit Defect Model
}

\author{
Inaugural-Dissertation \\ zur Erlangung der Doktorwürde \\ der Vetsuisse-Fakultät Universität Zürich
}

vorgelegt von

\section{Iska Miriam Dresing}

Tierärztin

aus Düsseldorf, Deutschland

genehmigt auf Antrag von

Prof. em. Dr. med. vet. Jörg A. Auer, Hauptreferent

PD Dr. med. Mohammad Tezval, Korreferent 


$$
\begin{gathered}
\text { Departement für Pferde } \\
\text { Klinik für Pferdechirurgie } \\
\text { der Vetsuisse-Fakultät Universität Zürich }
\end{gathered}
$$

Direktor: Prof. Dr. med. vet. Anton Fürst, Dipl. ECVS

Arbeit unter Leitung von Prof. em. Dr. med. vet. Jörg A. Auer

\title{
Evaluation of a press-fit Osteochondral Poly(ester-urethane) Scaffold in a Rabbit Defect Model
}

\author{
Inaugural-Dissertation \\ zur Erlangung der Doktorwürde \\ der Vetsuisse-Fakultät Universität Zürich
}

vorgelegt von

\section{Iska Miriam Dresing}

Tierärztin

aus Düsseldorf, Deutschland

genehmigt auf Antrag von

Prof. em. Dr. med. vet. Jörg A. Auer, Hauptreferent

PD Dr. med. Mohammad Tezval, Korreferent 


\section{Contents}

TITLE

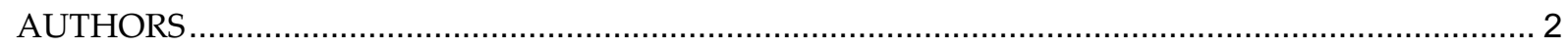

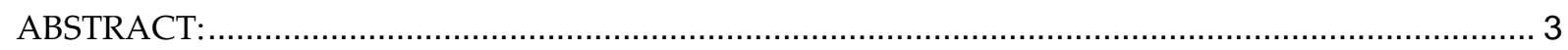

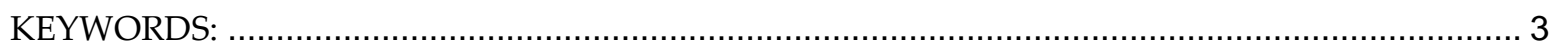

INTRODUCTION:

MATERIALS AND METHODS:

Poly(ester-urethane) and Scaffolds Preparation. ................................................................... 7

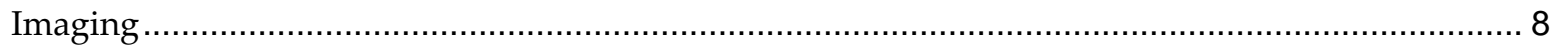

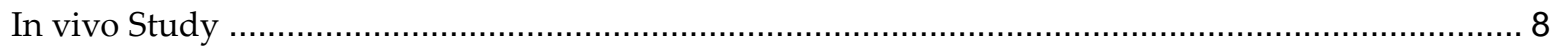

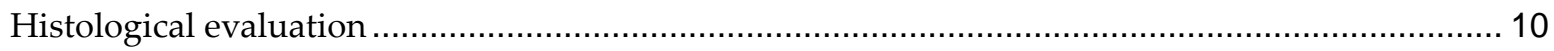

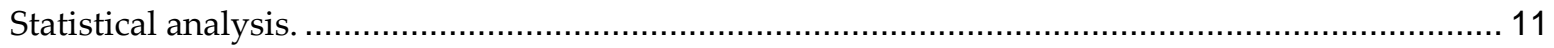

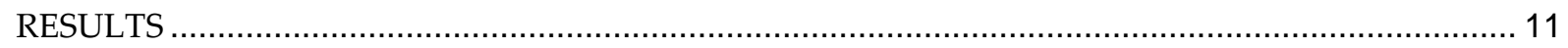

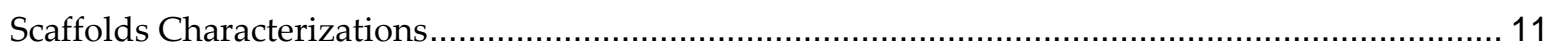

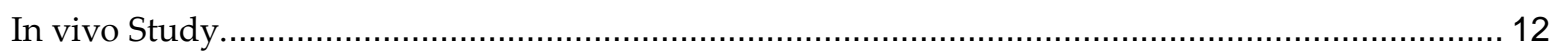

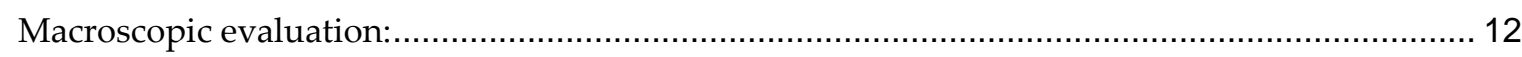

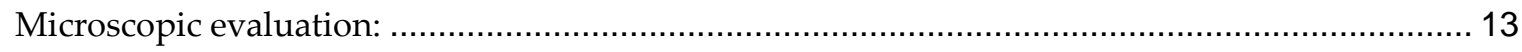

DISCUSSION

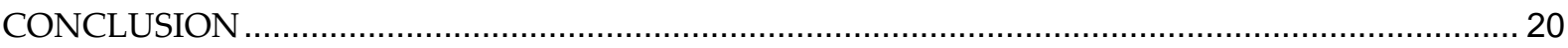

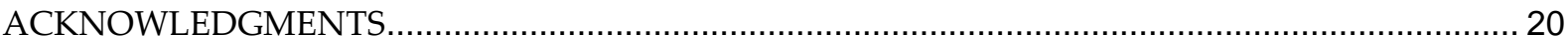

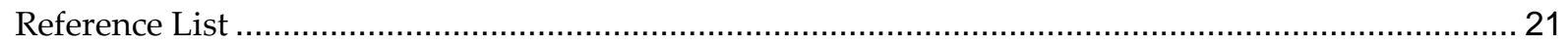

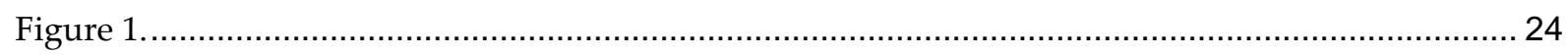

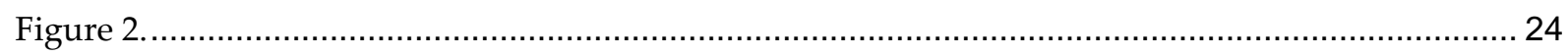

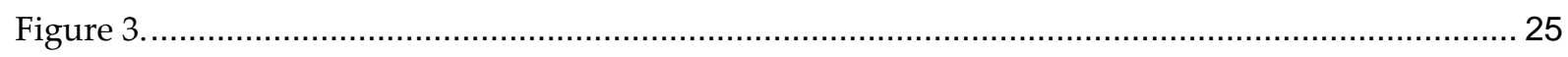

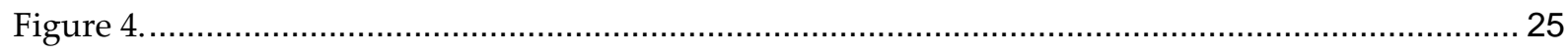

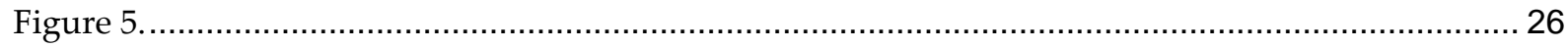

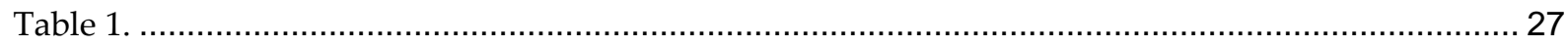

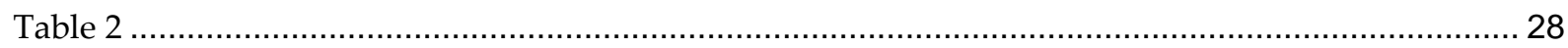

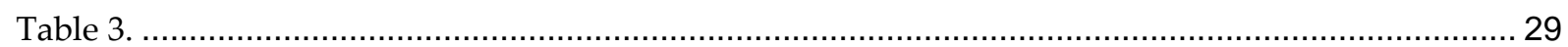

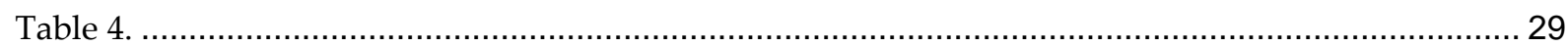


TITLE: Evaluation of a press-fit Osteochondral Poly(ester-urethane) Scaffold in a

\section{Rabbit Defect Model}

AUTHORS: Iska Dresing, ${ }^{1}$ Stephan Zeiter ${ }^{1}$, Jörg Auer ${ }^{2}$, Mauro Alini ${ }^{1}$, David Eglin ${ }^{1}$

1. AO Research Institute Davos, Clavadelerstrasse 8, 7270 Davos Platz, Switzerland.

2. Vetsuisse-Fakultät Universität Zürich, Winterthurerstrasse 204, 8057 Zürich,

Switzerland 


\section{ABSTRACT:}

The purpose of this study was to evaluate the impact on osteochondral healing of press-fitted multiphasic osteochondral scaffolds consisting of poly(ester-urethane) and hydroxyapatite into a cylindric osteochondral defect in the distal non-weight bearing femoral trochlear ridge of the rabbit.

Two scaffolds were investigated, one with and one without an intermediate microporous membrane between the cartilage and the bone compartment of the scaffold. A control group without a scaffold placed into the defect was included. After 12 weeks macroscopic and histomorphometric analyses were performed.

The scaffold was easily press-fitted and provided a stable matrix for tissue repair. The membrane did not demonstrate a detrimental effect on tissue healing compared with the scaffold without membrane. However, the control group had statistically superior healing as reflected by histological differences in the cartilage and subchondral bone compartment between control group and each scaffold group. A closer analysis revealed that the difference was localized in the bone compartment healing.

However, given the observed degree of healing in some of the animals in this study with the scaffold, the ease of its insertion and its stability, biodegradable elastomeric PUR/nHA scaffolds should be further investigated as potentially suitable carriers for a regenerative approach of articular cartilage injuries.

KEYWORDS: Osteochondral defect; Poly(ester-urethane);scaffold ;In vivo study;

Cartilage 


\section{INTRODUCTION:}

Articular cartilage is a very specialized connective tissue that functions as a natural weight bearing material, absorbing and transmitting loads across diarthrodial joints ${ }^{1}$. Once damaged due to trauma or diseases, articular cartilage has little self-healing capacity and this can lead to degenerative arthritis ${ }^{2,3}$. It is estimated that every fifth individual in industrialized countries is affected by arthritis or, numerically, 103 million Europeans, 6 million Canadians, and 46 million Americans suffer from osteoarthritis ${ }^{4-6}$.

The treatment of chondral or osteochondral defects in the articular surface consists of a step-by-step approach. The different treatment options, depend on the severity of the damage. Surgical interventions vary in their invasiveness and include different lavage techniques, debridement, abrasion chondroplasty, pridie drilling, microfracturing, corrective osteotomy or as end-stage treament total joint replacement. Another approach involves the use of biologics such as autologous chondrocyte transplantation, mosaicplasty or allogenic grafting7. Unfortunately, all these approaches have significant limitations including inferior quality of repair tissue, difficult surgical interventions, disease transmission, donor morbitiy or donor availability. Tissue engineering represents a promising treatment option to overcome at least some ofthese limitations ${ }^{8}$. The basis of tissue engineering involves the construction of a scaffold to provide a meachnical framework facilitating optimal tissue ingrowth and eventually repair. 
No consensus has yet been reached regarding the optimal design principles for osteochondral grafts, whether they are of autologous or tissue engineered origin. Scaffolds and their different compartments are engineered to provide mechanical stability, accommodate cells and drugs, and then guide tissue formation while resorbing with time and creating minimal adverse inflammatory reaction. With respect to tissue engineering solutions, various strategies have been developted for the scaffold material; from the preparation of mono- to multi-phasic structures ${ }^{9}$. To mimic this anatomy of the osteochondral structure, monophasic scaffolds are insufficient.

A tissue engineered bi-phasic scaffold made of an engineered cartilage and a calcium phosphate ceramic plug has been shown to be potentially superior for the repair of critical-size osteochondral defects in vivo $0^{10,11}$. However, the authors reported that correct positioning of the implant, with respect to both the cartilage and bone regions, was important for optimal repair and that the interface stability between the cartilage and bone compartment was critical.

To avoid damage of the sourrounding tissue as a result of interaction with the fixation technique (e.g. glue, suturing) of the scaffolds, scaffolds can be implanted using press-fit technique. This causes direct contact between tissue and scaffold and thereby improve the healing of the defect, and on the other hand avoid any negative interference with the native tissue. However, in the above study applying high force to press-fit the ceramic plug caused implant breakage and damage to the surrounding tissue. 
Segmented biodegradable Polyester-Urethane (PUR) have shown to be well suited for the fabrication of bone and cartilage grafts ${ }^{12-14}$. PUR scaffolds have superior biocompatibility, tuneable porosity, interconnected pores and elasticity ${ }^{14-16}$. The latter permits the use of press-fit technique to position the scaffold as previously discussed. The introduction of nano-size hydroxyapatite particles (nHA) as fillers in the PUR scaffold and the formation of an organic-inorganic composite lead to the improvement of both mechanical properties as well as of osteoconductive property ${ }^{12,}$ $15,17,18$. This has been shown in rabbits and sheep ${ }^{19,20}$.

Thus, the objective of this study was to compare a multiphasic osteochondral PUR scaffold to a biphasic scaffold and a control, consisting of a cartilage region and a bone osteoconductive region that can easily be press-fitted into an osteochondral defect. The difference between the two scaffolds is the addition of an intermediate barrier membrane in one of the scaffold types, incorporarted to allow diffusion of nutrition, but no vessel ingrowth and therewith prevent unwanted cartilage ossification and separate the needs of the two different tissues involved.

The scaffold consists of PUR in the cartilage and membrane compartment and of PUR with nHA in the bone compartment, differing in its porosity.

The scaffolds with and without membrane were implanted in an osteochondral defect in the distal non-weight bearing articular surface of the femur for 12 weeks. Macroscopic and histomorphometric analyses were performed to assess stability and press-fit of the scaffolds, the influence of the membrane and the different scaffold compartmens on the inflammation response as well as tissue repair. 


\section{MATERIALS AND METHODS:}

\section{Poly(ester-urethane) and Scaffolds Preparation.}

Unless stated otherwise, the chemicals were from Sigma-Aldrich, Milwaukee, WI. Degradable PUR was synthesized in a one-step solution polycondensation as described in the literature ${ }^{12}$. The PUR and nHA/PUR scaffolds were prepared by adapting a salt leaching-phase inverse technique already described in the literature ${ }^{12,}$ 12. The PUR and nHA/PUR blocks were water-jet cut (CUTEC AG, Basel-CH) to cylinders of $3 \mathrm{~mm}$ diameter and $0.5 \mathrm{~mm}$ and $5 \mathrm{~mm}$ height for the PUR and nHA/PUR scaffold respectively. The porous PUR membrane was prepared as follows: a polymer solution was prepared by dissolving $2 \mathrm{~g}$ of PUR in $10 \mathrm{~g}$ of solvent mixture composed of DMF and acetone with a ratio of 9:1 v:v. The PUR solution was released from a horizontally oriented syringe fitted with a steel needle (diameter $0.8 \mathrm{~mm}$ ), charged to $10 \mathrm{kV}$. The end of the needle was positioned $0.2 \mathrm{~m}$ away from the collecting surface, which consisted of a stationary copper plate covered with aluminum foil and charged to $5 \mathrm{kV}$.

The osteochondral scaffolds were assembled using a solvent welding technique. A DMF:acetone solvent mixture $(1: 3 \mathrm{v}: \mathrm{v})$ was prepared, the tip of the $\mathrm{nHA} / \mathrm{PUR}$ scaffold was soaked briefly in the solution and promptly pressed against the PUR membrane or scaffold. The same operation was performed after drying of the nHA/PUR-membrane scaffold for the welding of the PUR scaffold. After drying of the final osteochondral scaffolds for $24 \mathrm{hr}$ in air, each sample was trimmed with a scalpel for removal of imperfections and washed in an ethanol/ $\mathrm{ddH}_{2} \mathrm{O}(1: 1$ volume 
per volume) solution for $15 \mathrm{~min}$ and dried at room temperature, $30-40 \%$ humidity and finally under vacuum at $40^{\circ} \mathrm{C}$. The scaffolds were sterilized with ethylene oxide in a cold cycle $\left(37^{\circ} \mathrm{C}\right)$ and degassed under vacuum for at least 5 days prior to implantation.

\section{Imaging}

Osteochondral scaffold structures were imaged with a high-resolution microcomputed X-ray system ( $\mu \mathrm{CT}$ 40, Scanco Medical, Brüttisellen, Switzerland) as already reported ${ }^{12}$. The specimens were scanned at an energy of $45 \mathrm{kV}$ and an intensity of $176 \mu \mathrm{A}$. An integration time of $300 \mathrm{~ms}$ and 2-times averaging were used to enhance the signal-to-noise ratio to account for the low adsorption coefficient of PUR.

\section{In vivo Study}

The entire study was approved by the Veterinary Commission of the Canton of Grisons, Switzerland.

Eighteen skeletally mature (32 \pm 4 weeks old), female New Zealand White rabbits, weighing $4 \pm 0.4 \mathrm{~kg}$ were enrolled in this study. The rabbits were randomly allocated into 3 (n=6/group) groups. Group 1 served as control group, in group 2 a biphasic scaffold and group 3 a biphasic scaffold with a separating membrane between the two scaffold compartments was implanted.

Following premedication (medetomidin, midazolam, fentanyl) and induction (propofol 2\%) the rabbits underwent general anesthesia (isoflurane in oxygen). 
Perineural analgesia (lidocain $2 \%+$ bupivacain $0.5 \%$ ) was administered to the sciatic and femoral nerves.

The animals were placed in dorsal recumbency and the left stifle was prepared for aseptic surgery. A medial parapatellar arthrotomy was performed and the patella was luxated laterally to access the joint cavity with the leg in flexed position. A 1.25 mm diameter Kirschner-wire (Synthes no. 292.120) was inserted to the center of the medial trochlear ridge and overdrilled with a canulated $2.7 \mathrm{~mm}$ drill bit (Synthes, no. 310.670) with a fixed custom made drill depth limiter to create a $4 \mathrm{~mm}$ deep defect (Fig. 1). During this procedure the defect was continuously flushed with isotonic saline to avoid thermal damage of the surrounding tissue. Remaining tissue at the edges of the defect was carefully removed. A scaffold was either press-fit inserted into the defect, or the defect was left empty, depending on the group allocation (Fig. $1)$.

After reduction of the patella, the joint was closed routinely in three layers with absorbable suture material. Post operatively, the rabbits received buprenorphine (0,05mg/kg i.m/ q 12 hrs, Reckitt Benckiser AG)for 12 hrs, had a fentanyl patch (2 $\mu \mathrm{g} / \mathrm{kg} / \mathrm{hr}$, Mepha Pharma AG) in place for 72 days and received carprofen $(4 \mathrm{mg} / \mathrm{kg}$ s.c./ q 24 hrs, Pfizer AG) for 5 days. Immediately after surgery the rabbits were allowed to fully weight-bear and were housed in single cages. After one week they were then group-housed for the duration of the study. Clinical examinations were performed twice a day for the first 3 days, daily up to 7 days and weekly thereafter. 
The animals were euthanized 12 weeks after surgery via an intravenous overdose of a pentobarbital. The external body surface, all orifices and the external aspect of the surgery site were evaluated macroscopically by a veterinarian. Then the joint cavity was carefully opened and the defect macroscopically scored by two indepentend examiners using the "ICRS Cartilage Repair Assessment System" (Tab. 1)21, 22. The best possible score was 12 points. Depending on the score results, the healing was classified as normal (12), nearly normal (11-8), abnormal (7-4) or severely abnormal (3-1).

\section{Histological evaluation}

After macroscopic evaluation, the distal femora were immediately fixed in $70 \%$ methanol for $13-16$ days, decalcified with a $12.5 \%$ ethylendiaminetetraacetic acid + $1.25 \%$ sodium hydroxide solution for $51-54$ days and dehydrated with $50 \%$ ethanol. The samples were bisected perpendicular to the joint surface through the middle of the defect and embedded in paraffin. These embedded samples were then further sectioned in $5 \mu \mathrm{m}$ (Microm cool cut; model: HM 3555) slices and stained with either Haematoxylin and Eosin (H\&E) or Safranin-O and Fast green.

Histological findings were scored using a bright field light microscope (BX 40, Olympus, equipped with discussion unit U-DO3) with a score system (Tab. 2) adapted from O'Driscoll and the "Visual Histological Assessment Scale" by the International Cartilage Repair Society ${ }^{23,}{ }^{24}$. Additionally the authors appended evaluation of scaffold resorption and inflammation around the scaffold to these 
scales. This adapted score gives the opportunity to evaluate each slide in more detail and reproducibly.

The maximum score, indicative of normal healing, was 26 points, composed of a maximum score of 19 for the cartilage compartment and 7 for the subchondral bone. Additionally, the scaffold impact was scored with a maximum of 11 points for a fully resorbed scaffold without any granulomatous inflammation. Thus, the higher the score, the better the healing of the osteochondral defect.

In addition the defect closure was defined in percentage of the defect size. A fully closed defect $(100 \%)$ was stated with a score of $3,50 \%$ closure as a score of $2,25 \%$ as a score of 1 and a closure under $25 \%$ was assigned to a score of 0 .

\section{Statistical analysis.}

For statistical evaluation (SPSS) a Kruskal Wallis test followed by a Mann Whitney U Post-hoc test was performed (p 0.05). For multiple comparisons, Bonferroni correction was used to determine, if post hoc tests were significant. The following items were analysed comparing all 3 groups: ICRS macroscopic score values, healing of cartilage and/ or bone department. Overall microscopic score values including scaffold resorption and inflammation were compared between group 2 and 3 only.

\section{RESULTS}

\section{Scaffolds Characterizations}


The data on porosity, average pore size and stiffness of the cartilage and bone compartments as well as mechanical testing are reported in Table 3 and the architecture of the osteochondral scaffolds in Figure 2.

The cartilage compartment had a lower average pore size than the bone compartment with a similar porosity. The stiffness value of the bone compartment was higher than for the cartilage compartment even if the latter had a lower pore size value.

The cartilage region of the osteochondral scaffolds had qualitatively a lower pore size compared to the bone compartment. The nHA/PUR scaffold present regions of higher density, higher X-ray absorption and brighter intensity in the images compared to the PUR scaffold (Figs. 2 a and c). Quantitative analysis of the osteochondral scaffold was not performed due to the small size of the construct. However, the $\mu \mathrm{CT}$ analysis performed suggested conservation of the scaffold region structures except at the interface between the cartilage and bone compartments, where solvent welding may have caused the collapse of the pores structure.

\section{In vivo Study.}

All rabbits recovered well from surgery and all clinical exams were within normal limits for the duration of the entire study.

Macroscopic evaluation: No pathologic changes were detected neither in the surrounding cartilage nor macroscopic inflammation was observed in the joint cavity. At necropsy, no scaffold material was detected in the stifle joint in groups 2 or 3. In group 1, the median ICRS score was 10, with a range from 8.5 to 11 points, 
ranking the group as nearly normally healed. In group 2, the median score was 7.75 with score values ranging from 1 to 8.5 points, consistent with a marginally abnormal healing. Group 3, showed a macroscopic healing classified as abnormal healing with a median score of 5.25 and score values ranging from 2 to 11.5 points. The difference between groups 1 and 2 was statistically significant $(\mathrm{p}=0.004)$.

Microscopic evaluation: The histological assessment scores for the 3 groups are reported in Table 4 and Figure 4. Group 1 had a median histological score of 19, with a score range of 16 to 22 points. In the 6 animals of the control group, the defect closure was scored with 3 at week 12. The cartilage compartment showed notably good healing especially in terms of cellular morphology, structural integrity and thickness compared with the normal adjacent cartilage. Group 1 had shown the highest score of all 3 groups, despite the fact that the differentiation of the cartilage was not completed (Fig. 4). In the bone compartment, bone tissue was filling the defect in most of the cases (4/6). In one sample the defect was filled with fibrous tissue and with bone remodeling starting at the bottom of the defect. An intermediate state of healing was seen in one sample, were increased bone remodeling in form of an endochondral ossification was observed at the interface between bone and cartilage of the defect.

Group 2 showed a median healing with an average histological score of 15.5, and a range between 6 and 18. The closure of the defect was scored with 2.5, with a range between 0 and 3 . The cartilage compartment was clearly distinguishable with 2 of the 6 animals already showing hyaline like articular cartilage. In 2 cases, incompletely 
differentiated mesenchyme was observed and in the last two fibrous tissues was seen. In comparison, in the bone compartment of all 6 defects only granulation tissue was found. Bone ingrowth was starting in 2 out of 6 animal. Although bone tissue was not dominant yet. In 1 defect, the developing cartilage seemed to compress the scaffold and the scaffold was compressed into the bone compartment. In all rabbits the resorption of the scaffolds had started. Granulomatous inflammation in the cartilage compartment was in 1 animal high and moderate in 1 animal. However, no inflammation was seen in the cartilage compartment of the defect in 4 out of 6 rabbits. Only in 1 case was there no inflammation in the bone compartment. The average total inflammation score values were 7 , ranging from 6 to 10 .

In group 3, the median healing score value was 13.5, ranging from 6 to 20 (Fig. 4). The defect closure value was 2 , with a range from 0 to 3 points. The cartilage compartment showed in half of the cases hyaline-like cartilage, and in 2 cases, undifferentiated mesenchyme (2/6). In 1 of the animals, fibrous tissue filling the cartilage area of the defect was documented. In 1 of the animals, the scaffold seemed to compress into the bone area and was not visible in the cartilage compartment. In another one, the scaffold was compressed laterally by the ingrowing tissue. The median cartilage score was 9.5 with a range from 3 to 14 . In the bone compartment, granulation tissue was filling the bone area of the defect (6/6). In two rabbits cartilage-like tissue was visible in the granulation tissue, masking the scaffold. In half of the defects bone formation started, especially at the edges. Overall, granulation tissue was dominant. The bone compartment of all samples was histologically scored 
with 3. Finally, in all samples the resorption of the scaffold had started. Analyzing the foreign body reaction to the scaffold, the cartilage compartment reacted similar to group 2. In summary, the median score of the inflammation component of the scoring system was 6.5 with a range from 2 to 10. In 2 defects no inflammation could be seen and cartilage-like cells were covering the scaffold (as described above). In the other samples, moderate to high granulomatous inflammation was detected.

Statistical analysis of the histomorphometric scores of the cartilage and subchondral bone compartment indicated a significant difference between groups 1 and 2 $(p=0.006)$ and 1 and $3(p=0.009)$. Analysing the two compartments separately, $a$ significant difference between groups 1 and $2(p=0.015)$ and 1 and $3(p=0.015)$ was found for the subchondral bone compartment only. All other analyses of the histomorphometric score values did not show a significant difference.

\section{DISCUSSION}

Osteochondral defects in the medial trochlear ridge of the rabbit are a good model for proof-of-concept in vivo studies, screening therapeutic interventions aimed at cartilage healing ${ }^{25,26}$. The disadvantages of the model are the physical size limitations, the thin hyaline cartilage layer, and the potential spontaneous healing of rabbit cartilage even in large defect sizes.

Reviewing the literature regarding this spontaneous healing in rabbits uncovers controversial findings. On the one hand, the perception is that all tissues in rabbits heal despite critical size defects ${ }^{26,27}$. Others report that a complete healing does not 
take place ${ }^{26,28}$. Wei et al. reported for a defect of $3 \mathrm{~mm}$ in diameter and $3 \mathrm{~mm}$ depth that adult $(34 \pm 2.5$ weeks $)$ rabbits had a lower healing score compared to younger rabbits $^{29}$. To minimize the influence of age on spontaneous healing on the study results, mature $(32 \pm 4$ weeks) rabbits were used in this study. Skeletal maturity of rabbits is believed to occur within 16 to 39 weeks $^{25}$. It is also intuitive that the size of an osteochondral defect influences the healing capacity. Osteochondral defects reported in the literature have a diameter range of $3 \mathrm{~mm}$ to $5 \mathrm{~mm}$ and a depth of 2 to $5.5 \mathrm{~mm}^{24,27,30,31}$.

In this study, a $2.7 \mathrm{~mm}$ diameter, $3 \mathrm{~mm}$ in deep osteochondral defect was considered to be appropriate to assess the press-fit scaffold stability in the defect and the tissues' reaction to the scaffold materials and architectures. To assess the influence of the scaffold on the healing process, a control group without a scaffold filling the defect was included in this study.

Inserting the PUR/nHA/PUR scaffolds by press-fitting provided uniform, direct and tight contact between scaffold material and host tissue and it increased mechanical stability without the need of sutures or a glue that could further damage tissue or impede tissue repair ${ }^{31,32}$. None of the implanted scaffolds had migrated into the knee cavity after 12 weeks of implantation. This was similar to what was found by Hannink et al., suggesting that elastomeric scaffolds provide an excellent press-fit and in vivo stability in relatively large osteochondral defects ${ }^{20}$.

While there was no significance between the scaffold groups at 12 weeks, there was a significant difference of lower macroscopic score values for the scaffold groups 
compared to the control. This is not surprising considering that in a similar in vivo study it was shown that after 12 weeks the remains of a slow resorbable poly( $\varepsilon$ caprolactone) scaffold could influence cartilage repair tissue appearance ${ }^{31}$.

Microscopic histological evaluation indicated again a significant difference with a lower score for the scaffold groups compared to the control group. Further, the hypothesized beneficial effect of a micro-porous separating membrane between the two compartments of the scaffold could not be shown. No significant differences in histological evaluation of the cartilage compartment was found between groups 2 and 3. The histological evaluation revealed that in most of the animals the cartilagebone interface of the scaffold with or without membrane was not positioned at the cartilage-subchondral bone interface, but deeper in the defect, and not properly aligned and often undulated. Presumably this occurred because of (size) limitations of the animal model and the scaffold fabrication. The cartilage thickness of the distal medial trochlea in rabbits is $306 \pm 30 \mu \mathrm{m}$ thick, which makes it very challenging to reproduce with the fabrication techniques used for the PUR scaffolds ${ }^{33}$; in this study the cartilage compartment was nearly twice as thick. It is very likely that even without considering cartilage thickness variations in rabbits, the interface of the multiphasic scaffolds could seldom be adjusted to the osteochondral tissue architecture. Morever, the press-fitting of the $3 \mathrm{~mm}$ diameter scaffold into the $2.7 \mathrm{~mm}$ diameter defect is likely the cause the membrane undulation (Fig. 4, group 3).

In this study a cell-free approach was choosen to test only the scaffolds. However, it is likely that the combination of a cell and osteochondral scaffold matrix approach 
may be needed for successful healing of articular cartilage and osteochondral defects $^{34}$. If the scaffold is seeded with cells, the effect of the membrane should be reevaluated. Clearly, precise and high-resolution fabrication techniques (e.g. Stereolithography) would be needed for creating multiphasic scaffolds in the small dimensions needed for use in rabbits. Alternatively, the problem may be solved when using large animal models or in human clinical cases, due to thicker cartilage layer and the larger defect sizes $8,25,33$.

The histological evaluation also yielded further information on the healing process and the influence of the scaffolds. The cartilage compartment of groups 2 and 3 yielded wider ranges of score values that were more similar to those seen for the bone compartment scores. In fact, the repair score for the bone compartment was consistently 3 for groups 2 and 3 . Granulation tissue had grown into the bone compartment of the scaffold with, in some cases, cartilage-like tissue covering the scaffold. The bony ingrowth in the distal part and the edges of the multiphasic scaffolds occurred via endochondral ossification ${ }^{35}$. This suggests that the nHA/PUR scaffolds do not induce significant bone ingrowth and may have poor osteoconductive property even in the presence of nHA particles at the macro-pore surfaces. This may also be related to the relatively low mechanical properties of the HA/PUR scaffolds compared to bone tissue, even if a reinforcing effect of the nanoparticles of hydroxyapatite in the polymeric phase could be previously shown (Tab. 3). The low stiffness of the scaffolds may direct the repair-cells mobilized in the 
defect during the injury (mesenchymal stromal cells) toward cartilaginous and fibrous tissues.

However, a potentially more important finding is the immunologic response to the material implanted in the defect. In a previous study by Laschke et al., PUR and nHA/PUR scaffolds were tested in a dorsal skin chamber model of BALB/c mice. Good biocompatibility was observed ${ }^{17}$, 18 . In contrast, in the present study, signs of inflammation in both PUR and nHA/PUR scaffold compartments were observed. Multinucleated giant cells as a sign of a chronic granulomatous inflammation and foregin body reaction were seen histologically. After 12 weeks, low granulomatous inflammation around the scaffolds was detected in a few samples. Some other samples did have a moderate or high amount of multinucleated giant cells, indicating ongoing inflammation. Although the observed inflammation towards the scaffold is adverse for tissue healing, inflammation is an important step towards tissue repair. Schlichting et al. detected a large number of polynuclear giant cells phagocytosing after 12 weeks and a large volume of remaining scaffold in the presence of good tissue regeneration. After 6 months, only a small amount of scaffold was present at the base of the defect ${ }^{36}$. Thus, it may be expected that repair of the osteochondral defect in the presence of the PUR scaffolds could heal similary if given more time. This is very possible as the authors observed several instances where inflammation was overcome and cartilage-like cells were covering the scaffold. Given more time, endochondral ossification could have filled the subchondral bone compartment with new bone . 


\section{CONCLUSION}

The present study demonstrates that an elastomeric PUR scaffold can easily be pressfitted into an osteochondral defect and provide a stable matrix for tissue repair. However, the multi-phasic scaffold did not provide a clear advantage for tissue healing here, mainly due to the difficulty in accurately aligning the complex scaffold with the host tissue. Future investigations should refine the bone phase of the implant to increase its stiffness, biocompatibility and osseoconductive activity, and a more precise fabrication technique would be necessary.

\section{ACKNOWLEDGMENTS}

Markus Glarner for his help in the synthesis and preparation of Poly(ester-urethane) scaffolds. Dr. Giuseppino Fortunato from EMPA St-Gallen, Switzerland for the processing of the electrospun PUR membranes, Dr. Dirk Nerhbass and Nora Goudsouzian for the help with the histological processing and analysis of the samples. And the team of the Preclinical Facility of the AO-Research Institute for the support while performing the in vivo part of this study. The authors are supported by a consortium grant from the AO Exploratory Research Board.

We wish to confirm that there are no known conflicts of interest associated with this publication and there has been no significant financial support for this work that could have influenced its outcome. 


\section{Reference List}

1. Muir H. The chondrocyte, architect of cartilage. Biomechanics, structure, function and molecular biology of cartilage matrix macromolecules. Bioessays 1995;17:1039-1048.

2. Bonzani IC, George JH, Stevens MM. Novel materials for bone and cartilage regeneration. Curr Opin Chem Biol 2006;10:568-575.

3. Chiang H, Jiang CC. Repair of articular cartilage defects: review and perspectives. J Formos Med Assoc 2009;108:87-101.

4. Brittberg M, Lindahl A, Nilsson A, Ohlsson C, Isaksson O, Peterson L. Treatment of deep cartilage defects in the knee with autologous chondrocyte transplantation. N Engl J Med 1994;331:889-895.

5. Dunlop DD, Manheim LM, Yelin EH, Song J, Chang RW. The costs of arthritis. Arthritis Rheum 2003;49:101-113.

6. Helmick CG, Felson DT, Lawrence RC, Gabriel S, Hirsch R, Kwoh CK, Liang MH, Kremers HM, Mayes MD, Merkel PA and others. Estimates of the prevalence of arthritis and other rheumatic conditions in the United States. Part I. Arthritis Rheum 2008;58:15-25.

7. Hunziker EB. Articular cartilage repair: basic science and clinical progress. A review of the current status and prospects. Osteoarthritis Cartilage 2002;10:432-463.

8. Martin I, Miot S, Barbero A, Jakob M, Wendt D. Osteochondral tissue engineering. J Biomech 2007;40:750-765.

9. Nooeaid P, Salih V, Beier JP, Boccaccini AR. Osteochondral tissue engineering: scaffolds, stem cells and applications. J Cell Mol Med 2012;16:2247-2270.

10. Kandel RA, Grynpas M, Pilliar R, Lee J, Wang J, Waldman S, Zalzal P, Hurtig M. Repair of osteochondral defects with biphasic cartilage-calcium polyphosphate constructs in a sheep model. Biomaterials 2006;27:4120-4131.

11. Schaefer DJ, Klemt C, Zhang XH, Stark GB. [Tissue engineering with mesenchymal stem cells for cartilage and bone regeneration]. Chirurg 2000;71:1001-1008.

12. Boissard CI, Bourban PE, Tami AE, Alini M, Eglin D. Nanohydroxyapatite/poly(ester urethane) scaffold for bone tissue engineering. Acta Biomater 2009;5:3316-3327.

13. Eglin D, Grad S, Gogolewski S, Alini M. Farnesol-modified biodegradable polyurethanes for cartilage tissue engineering. J Biomed Mater Res A 2010;92:393-408.

14. Grad S, Kupcsik L, Gorna K, Gogolewski S, Alini M. The use of biodegradable polyurethane scaffolds for cartilage tissue engineering: potential and limitations. Biomaterials 2003;24:5163-5171.

15. Hofmann A, Ritz U, Verrier S, Eglin D, Alini M, Fuchs S, Kirkpatrick CJ, Rommens PM. The effect of human osteoblasts on proliferation and neo-vessel formation of human umbilical vein endothelial cells in a long-term 3D co-culture on polyurethane scaffolds. Biomaterials 2008;29:4217-4226. 
16. Lee CR, Grad S, Gorna K, Gogolewski S, Goessl A, Alini M. Fibrin-polyurethane composites for articular cartilage tissue engineering: a preliminary analysis. Tissue Eng 2005;11:15621573.

17. Laschke MW, Strohe A, Scheuer C, Eglin D, Verrier S, Alini M, Pohlemann T, Menger MD. In vivo biocompatibility and vascularization of biodegradable porous polyurethane scaffolds for tissue engineering. Acta Biomater 2009;5:1991-2001.

18. Laschke MW, Strohe A, Menger MD, Alini M, Eglin D. In vitro and in vivo evaluation of a novel nanosize hydroxyapatite particles/poly(ester-urethane) composite scaffold for bone tissue engineering. Acta Biomater 2010;6:2020-2027.

19. Deplaine H, Lebourg M, Ripalda P, Vidaurre A, Sanz-Ramos P, Mora G, Prosper F, Ochoa I, Doblare M, Gomez Ribelles JL and others. Biomimetic hydroxyapatite coating on pore walls improves osteointegration of poly(L-lactic acid) scaffolds. J Biomed Mater Res B Appl Biomater 2013;101:173-186.

20. Hannink G, de Mulder EL, van Tienen TG, Buma P. Effect of load on the repair of osteochondral defects using a porous polymer scaffold. J Biomed Mater Res B Appl Biomater 2012;100:2082-2089.

21. Brittberg M, Winalski CS. Evaluation of cartilage injuries and repair. J Bone Joint Surg Am 2003;85-A Suppl 2:58-69.

22. van den Borne MP, Raijmakers NJ, Vanlauwe J, Victor J, de Jong SN, Bellemans J, Saris DB. International Cartilage Repair Society (ICRS) and Oswestry macroscopic cartilage evaluation scores validated for use in Autologous Chondrocyte Implantation (ACI) and microfracture. Osteoarthritis Cartilage 2007;15:1397-1402.

23. Mainil-Varlet $P$, Aigner T, Brittberg M, Bullough P, Hollander A, Hunziker E, Kandel R, Nehrer $\mathrm{S}$, Pritzker K, Roberts $\mathrm{S}$ and others. Histological assessment of cartilage repair: a report by the Histology Endpoint Committee of the International Cartilage Repair Society (ICRS). J Bone Joint Surg Am 2003;85-A Suppl 2:45-57.

24. O'Driscoll SW, Keeley FW, Salter RB. Durability of regenerated articular cartilage produced by free autogenous periosteal grafts in major full-thickness defects in joint surfaces under the influence of continuous passive motion. A follow-up report at one year. J Bone Joint Surg Am 1988;70:595-606.

25. Ahern BJ, Parvizi J, Boston R, Schaer TP. Preclinical animal models in single site cartilage defect testing: a systematic review. Osteoarthritis Cartilage 2009;17:705-713.

26. Rudert M. Histological evaluation of osteochondral defects: consideration of animal models with emphasis on the rabbit, experimental setup, follow-up and applied methods. Cells Tissues Organs 2002;171:229-240.

27. Shapiro F, Koide S, Glimcher MJ. Cell origin and differentiation in the repair of full-thickness defects of articular cartilage. J Bone Joint Surg Am 1993;75:532-553.

28. Furukawa T, Eyre DR, Koide S, Glimcher MJ. Biochemical studies on repair cartilage resurfacing experimental defects in the rabbit knee. J Bone Joint Surg Am 1980;62:79-89. 
29. Wei X, Gao J, Messner K. Maturation-dependent repair of untreated osteochondral defects in the rabbit knee joint. J Biomed Mater Res 1997;34:63-72.

30. Frenkel SR, Bradica G, Brekke JH, Goldman SM, Ieska K, Issack P, Bong MR, Tian H, Gokhale J, Coutts RD and others. Regeneration of articular cartilage--evaluation of osteochondral defect repair in the rabbit using multiphasic implants. Osteoarthritis Cartilage 2005;13:798-807.

31. Shao X, Goh JC, Hutmacher DW, Lee EH, Zigang G. Repair of large articular osteochondral defects using hybrid scaffolds and bone marrow-derived mesenchymal stem cells in a rabbit model. Tissue Eng 2006;12:1539-1551.

32. Kock NB, Van Susante JL, Buma P, Van KA, Verdonschot N. Press-fit stability of an osteochondral autograft: Influence of different plug length and perfect depth alignment. Acta Orthop 2006;77:422-428.

33. Frisbie DD, Cross MW, Mcllwraith CW. A comparative study of articular cartilage thickness in the stifle of animal species used in human pre-clinical studies compared to articular cartilage thickness in the human knee. Vet Comp Orthop Traumatol 2006;19:142-146.

34. Yang PJ, Temenoff JS. Engineering orthopedic tissue interfaces. Tissue Eng Part B Rev 2009;15:127-141.

35. Zoetis T, Tassinari MS, Bagi C, Walthall K, Hurtt ME. Species comparison of postnatal bone growth and development. Birth Defects Res B Dev Reprod Toxicol 2003;68:86-110.

36. Schlichting K, Schell H, Kleemann RU, Schill A, Weiler A, Duda GN, Epari DR. Influence of scaffold stiffness on subchondral bone and subsequent cartilage regeneration in an ovine model of osteochondral defect healing. Am J Sports Med 2008;36:2379-2391. 


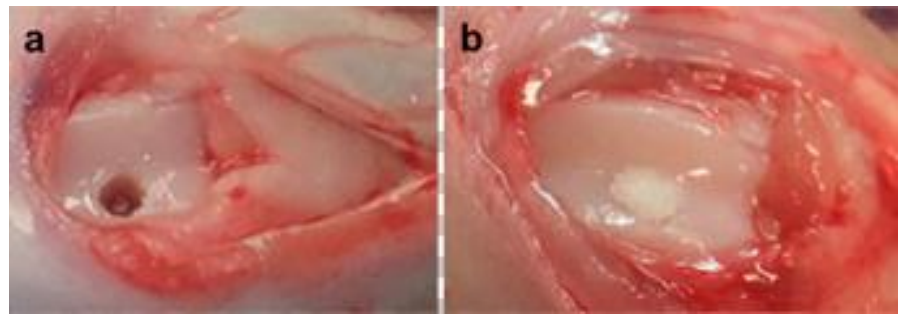

Figure 1. Left femur intra operative, medial trochlear ridge with defect, a: empty defect; b: scaffold in-situ.

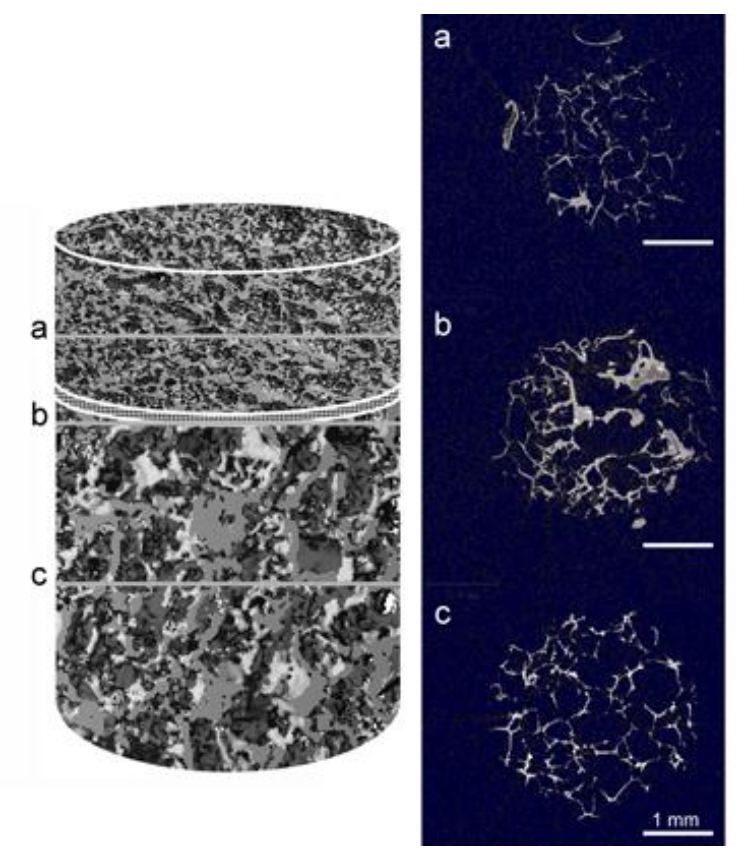

Figure 2. Schematic of the osteochondral scaffolds with a cartilage compartment (a), an intermediate membrane (b) and a bone compartment, and representative $\mu \mathrm{CT}$ slice of the respective scaffold regions (Contrast in the $\mu \mathrm{CT}$ images was enhanced $a$ posteriori for improved viewing). 


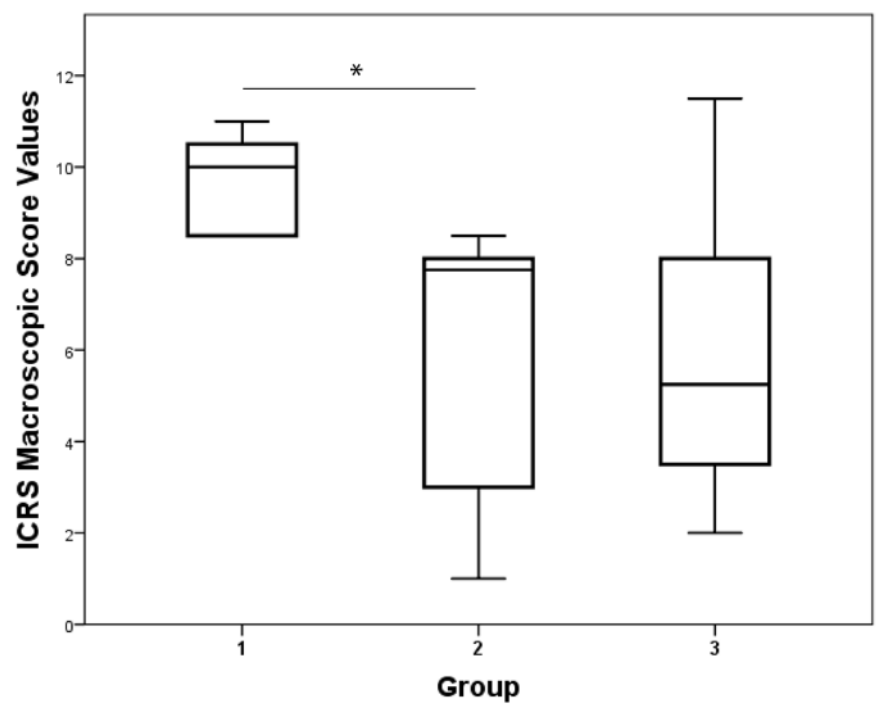

Figure 3. Box plots of ICRS ME Score values of group 1, group 2 and group 3; $\mathrm{n}=6$ /group, statistic: On-way ANOVA and Bonferroni Post-hoc tests at $(\mathrm{p}<0.05)$ did not indicate differences between groups.

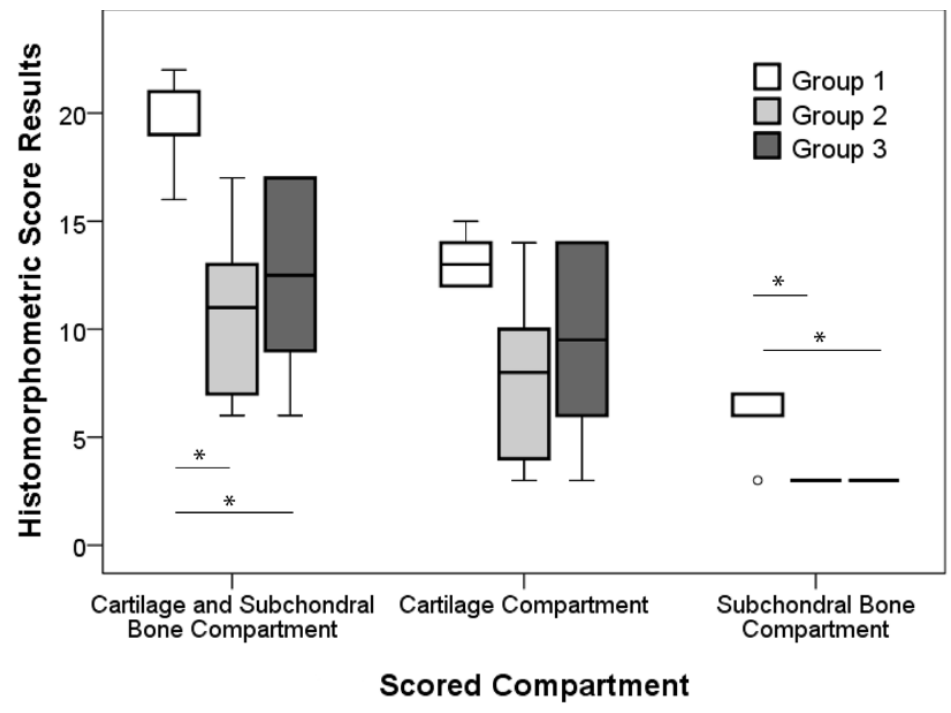

Figure 4. Bar diagramm of the histomorphometric scores of group 1, group 2 and group 3 showing the reached scores for the cartilage and bone compartment in summary and for each compartment. 

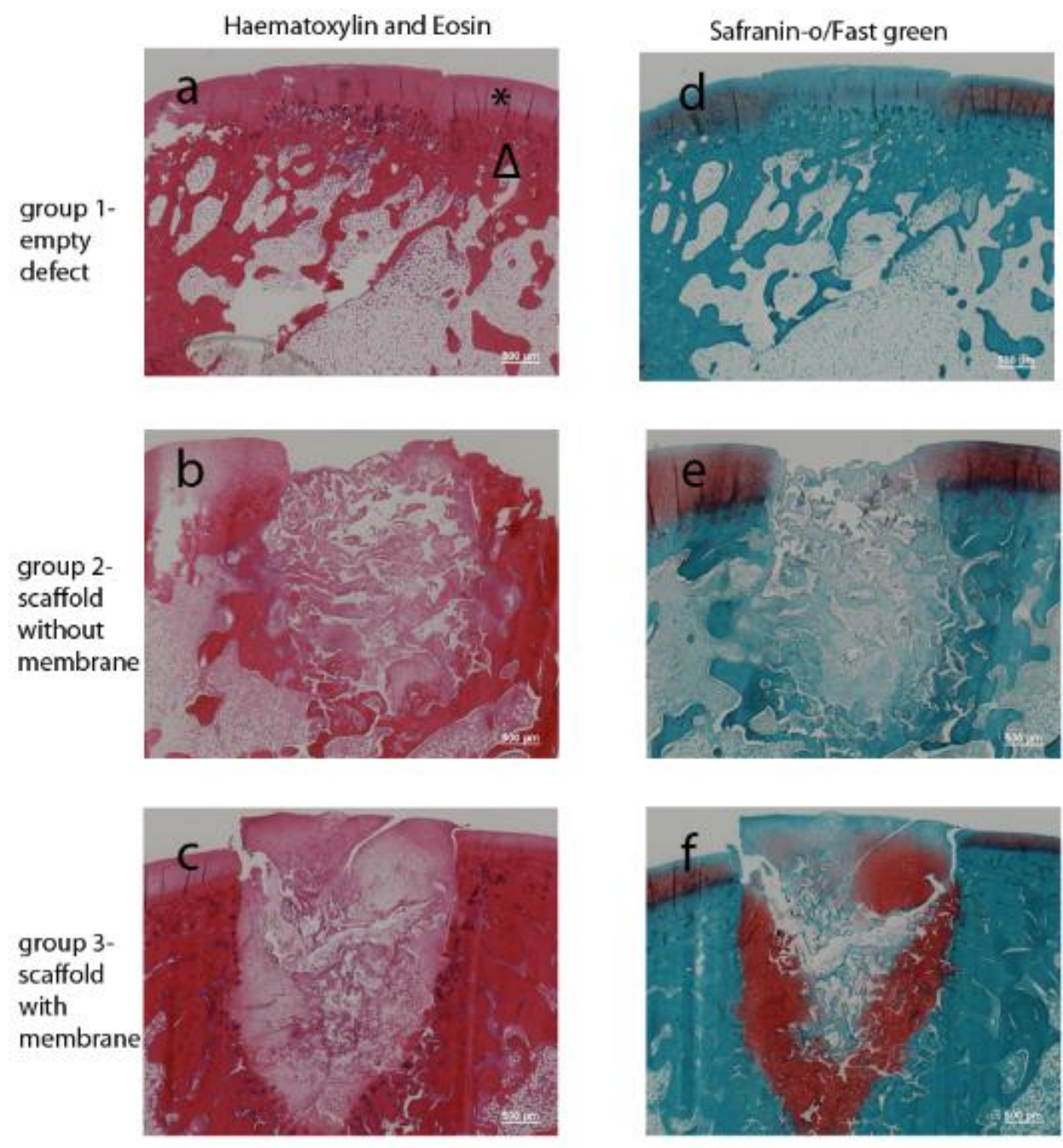

Figure 5. Representative Hematoxylin and Esoin and Safranin-O Fast green stained histological images of the osteochodndral defect at 12 weeks post op with the histological score the closest to the average value of the respective groups: group 1 $(\mathrm{a}, \mathrm{d})$; group $2(\mathrm{~b}, \mathrm{e})$ and group $3(\mathrm{c}, \mathrm{f})$. Magnification x25 (* cartilage compartment $\mathrm{A}$ subchondral bone compartment). 
Table 1. "ICRS Cartilage Repair Assessment System" for macroscopic evaluation of the defect healing ${ }^{21,22}$.

\begin{tabular}{|c|c|}
\hline ICRS cartilage repair assessment & Score \\
\hline \multicolumn{2}{|l|}{ Degree of defect repair } \\
\hline In level with surrounding cartilage & 4 \\
\hline $75 \%$ repair of defect depth & 3 \\
\hline $50 \%$ repair of defect depth & 2 \\
\hline $25 \%$ repair of defect depth & 1 \\
\hline $0 \%$ repair of defect depth & 0 \\
\hline \multicolumn{2}{|l|}{ Integration to border zone } \\
\hline Complete integration with surrounding cartilage & 4 \\
\hline Demarcating border $<1 \mathrm{~mm}$ & 3 \\
\hline $3 / 4$ of graft integrated, $1 / 4$ with notable border $>1 \mathrm{~mm}$ width & 2 \\
\hline $\begin{array}{l}1 / 2 \text { of graft integrated with surrounding cartilage, } 1 / 2 \text { with notable border }>1 \\
\mathrm{~mm}\end{array}$ & 1 \\
\hline From no contact to $1 / 4$ of graft integrated with surrounding cartilage & 0 \\
\hline \multicolumn{2}{|l|}{ Macroscopic appearance } \\
\hline Intact smooth surface & 4 \\
\hline Fibrillated surface & 3 \\
\hline Small, scattered fissures or cracks & 2 \\
\hline Several small or few but large fissures & 1 \\
\hline Total degeneration of grafted area & 0 \\
\hline \multicolumn{2}{|l|}{ Overall repair assessment } \\
\hline Grade I: normal & 12 \\
\hline Grade II: nearly normal & $11-8$ \\
\hline Grade III: abnormal & $7-4$ \\
\hline Grade IV: severely abnormal & $3-1$ \\
\hline
\end{tabular}


Table 2. Histological grading score adapted from O'Driscoll and ICRS ${ }^{23,24}$

\section{Histomorphometric score system to evaluate osteochondral defect repair}

Nature of the predominant tissue

Staining: $H \& E$, Safranine- $O$

Score

I cartilage compartment

I.1. Cellular morphology

Hyaline articular cartilage 4

Incompletely differentiated mesenchyme 2

Fibrous tissue or bone $\quad 0$

Safranin- $O$ staining of the matrix

Normal or nearly normal $\quad 3$

Moderate 2

Slight 1

None 0

I.2. Structural characteristics

I.2.1. Surface regularity

Smooth and intact 3

Superficial horizontal lamination 2

Fissures $25-100 \%$ of thickness 1

Severe disruption, including fibrillation 0

I.2.2. Structural integrity

Normal or nearly normal 2

Slight disruption, including cysts 1

I.2.3. Thickness

Severe disintegration 0

$100 \%$ of normal adjacent 2

$50-100 \%$ of normal cartilage 1

I.3. Bonding to the adjacent cartilage

$<50 \%$ of normal cartilage $\quad 0$

I.3.1. Hypocellularity

Normal cellularity 3

Slight hypocellularity 2

Moderate hypocellularity 1

I.3.2. chondrocyte clustering

Severe hypocellularity 0

No cluster 2

$<25 \%$ of the cells 1

$25-100 \%$ of the cells 0

II Subchondral bone $\quad / 7$

II.1. Appearance

Normal 3

Increased remodeling 2

Bone necrosis/granulation tissue 1

Detached/fracture/callus at base 0

II.2. Cellular morphology

Bone 4

Fibrous tissue 2

\section{Scaffold}

III.1. Resorption

Totally resorbed 3

Beginning degradation 2

Amount unchanged 1 
III.2. Granulomatous inflammation

III.2.1. Cartilage compartment

$\begin{array}{ll}\text { No } & 4 \\ \text { Low } & 3 \\ \text { Moderate } & 2 \\ \text { High } & 1 \\ \text { tment } & \\ \text { No } & 4 \\ \text { Low } & 3 \\ \text { Moderate } & 2 \\ \text { High } & 1\end{array}$

Table 3. List of structural and mechanical properties of PUR and nHA/PUR scaffolds and membrane properties ${ }^{12}$.

\begin{tabular}{lllll}
\hline $\begin{array}{l}\text { Scaffold } \\
\text { Region }\end{array}$ & Material & $\begin{array}{l}\text { Average pore } \\
\text { size }(\boldsymbol{\mu m})\end{array}$ & Porosity (\%) & $\begin{array}{l}\text { Stiffness } \\
(\mathbf{N} / \mathbf{m m})\end{array}$ \\
\hline Cartilage & PUR Salt & 121 & 85 & $0.98(0.04)$ \\
& leaching & & & \\
\hline $\begin{array}{l}\text { Subchondral } \\
\text { bone }\end{array}$ & Electrospun & Micron-size fibers with pore size $\leq 10 \mu \mathrm{m}, 0.1 \mathrm{~mm}$ \\
\hline Cortical bone & PUR & thickness & & $2.18(0.06)$ \\
& Leaching & & 87 & \\
\hline
\end{tabular}

Table 4. Table of the histomorphometric scores of group 1, group 2 and group 3 showing the reached scores for scaffold resorption, foregin body inflammation and defect closure.

\begin{tabular}{lcccccccrr} 
& \multicolumn{3}{c}{ Group 1 } & \multicolumn{3}{c}{ Group 2 } & \multicolumn{3}{c}{ Group 3 } \\
& med & $\min$ & $\max$ & med & $\operatorname{mini}$ & $\max$ & med & $\min$ & $\max$ \\
\hline Scaffold resorption & $/$ & $/$ & $/$ & 2 & 2 & 2 & 2 & 2 & 2 \\
$\begin{array}{l}\text { Foreign body } \\
\text { inflammation }\end{array}$ & $/$ & $/$ & $/$ & 7 & 6 & 12 & 5.5 & 2 & 8 \\
Defect closure & 3 & 3 & 3 & 2.5 & 0 & 3 & 2 & 0 & 3 \\
\hline
\end{tabular}





\section{Curriculum Vitae}

Name, Vorname

Geburtsdatum

Geburtsort

Nationalität

\section{Höchster Schulabschluss}

24.Juni 2005

Abitur

\section{Studium}

Okt. 2005 - März 2011 Tiermedizin, Tierärztliche Hochschule Hannover/D

\section{Abschlussprüfung vet. med.}

10. März 2011

Staatsexamen, Tierärztliche Hochschule Hannover/D

\section{Anfertigung der Dissertation}

August 2012 - Mai 2013 unter Leitung von Prof. em. Dr. med. vet. Jörg Auer, Department für Pferde, Vetsuisse-Fakultät UZH

\section{Fachrelevanten Anstellungen}

nach Abschluss des Vet-Med.-Studiums

April 2011-Sept. 2011 AO Research Institute, Research Fellow Focus Area Surgery, Preclinical Services, Davos/CH

Seit Okt. 2011 